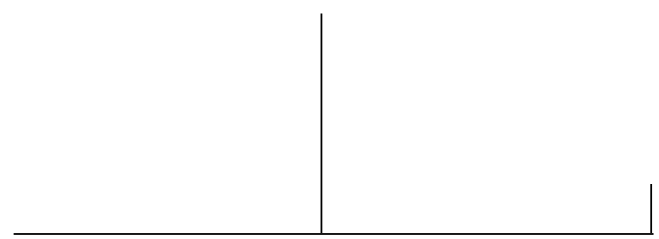

Rev. Latinoam. Psicopat. Fund., São Paulo, v. 15, n. 3, p. 647-648, setembro 2012 (Suplemento)

\title{
Editorial
}

\section{Supplement on Eating Disorders}

\author{
Manoel Tosta Berlinck
}

This special edition of the Latin-American Journal of Fundamental Psychopathology offers its readers a number of texts by Brazilian clinicians with vast experience in psychotherapy and research related to eating disorders. All the papers published here were presented at the Fifth International Congress of Fundamental Psychopathology and the Eleventh Brazilian Congress of Fundamental Psychopathology, whose specific theme was eating disorders. The congress, held at the Ponta Mar Hotel in Fortaleza, Ceará, Brazil, from September 5th to 9th, 2012, brought together over 500 professionals and students from many different countries, and evidenced the importance of this type of psychopathology, which affects growing numbers of persons in the world today. The articles here deal with the topic from different approaches, showing its multiconceptual nature. In the world of psychotherapy and clinical research that takes subjectivity into account, we cannot expect to find a single practical and conceptual approach. It is therefore easy to see the need for publications that describe advances in the research and that promote discussion among professionals who use the various approaches. 
The editors and staff at the Latin-American Journal of Fundamental Psychopathology feel pleased that the publication is propitiating the diffusion of different approaches in psychopathology. For this reason, we feel honored to be able to publish work by Brazilian authors of such high scientific expertise. 